\title{
Schopenhauer e a crítica de Walter Benjamin à noção romântica de alegoria
}

\author{
Rosa Gabriella de Castro Gonçalves*
}

Resumo: O objetivo do texto é discutir a separação entre linguagem e estética na filosofia de Schopenhauer a partir da crítica feita por Walter Benjamin em Origem do Drama Barroco Alemão à concepção romântica de alegoria.

Palavras-chave: símbolo - alegoria - Idéia - conceito

"Se o objetivo de toda arte é a comunicação da idéia apreendida...; se além disso partir do conceito é algo de condenável na arte, não se pode aprovar a prática explícita e proposital de usar uma obra de arte para a expressão de um conceito: é o caso da alegoria... Se portanto uma imagem alegórica tem também valor artístico, este é distinto e independente do valor que possa ter enquanto alegoria. Uma obra de arte deste gênero tem portanto um duplo fim, exprimir um conceito e exprimir uma idéia. Somente o último pode ser um fim artístico. O primeiro é um fim estranho à arte, uma diversão frívola que consiste em construir uma imagem que sirva também como inscrição, à guisa de hieróglifo... Sem dúvida, uma imagem alegórica pode enquanto tal suscitar uma viva impressão no espírito, mas o mesmo efeito teria sido induzido, nas mesmas circunstâncias, por uma inscrição"1

Este texto de Schopenhauer foi escolhido por Walter Benjamin, em Origem do Drama Barroco Alemão, para ilustrar como a noção romântica de alegoria era equivocada e, em que medida não compreender a alegoria como uma forma verdadeiramente artística e expressiva representava uma herança do Classicismo.

Tomando a alegoria como uma transgressão inadmissível das fronteiras

* Mestranda do Departamento de Filosofia - FFLCH-USP e bolsista CAPES. 
entre as artes visuais e a escrita, o Classicismo não teria se dado conta da síntese operada pela alegoria a partir do símbolo teológico e da forma artística. O Romantismo, ao forjar um conceito profano de símbolo, o qual estendeu também à alegoria, teria ignorado sua função originalmente didática, que implicava em contribuir para a educação religiosa num momento no qual teria sido preciso destruir uma iconologia muito marcante, herdada da Antiguidade.

Se interpretarmos a obra de Walter Benjamin como uma historiografia crítica, veremos que esta é construída predominantemente pela superposição de imagens de diferentes períodos. Alegorias, imagens de pensamento e imagens dialéticas aparecem em seus textos simultaneamente como instrumentos para conhecer e como objetos a serem estudados por estarem impregnadas não apenas pela história, como também por aquilo que esta oculta, sendo capazes de revelar $\mathrm{o}$ esquecido e o encoberto. $\mathrm{O}$ passado como algo estanque, o encadeamento causal e a cronologia não lhe interessavam. Contrapunha ao mito fixado pelo historicismo uma história inacabada, capaz de estabelecer um diálogo entre o passado e o presente no qual este passado é estudado.

Em Origem do Drama Barroco Alemão este projeto historiográfico é guiado por princípios estabelecidos numa teoria do conhecimento exposta na primeira parte da obra. Trata-se de um estudo aprofundado dessa forma dramática e da sua linguagem, a alegoria e, ao mesmo tempo, de uma crítica ao mito com o qual Benjamin identificava a República de Weimar. As tentativas de restaurar o classicismo e de resgatar uma tradição cultural que viesse restituir alguma identidade a um mundo fora dos eixos pareciam, aos olhos de Benjamin, uma insistência em ignorar a impotência de tais ideais face às calamidades da guerra que só poderiam produzir análises equivocadas da cultura. Em resposta a este tipo de análise Benjamin escolheu seu objeto, o Barroco, um período negligenciado pelos estudiosos, como verdadeiro antagonista do Classicismo, título que sempre coubera ao Romantismo.

Benjamin apontou como função do Drama Barroco a legitimação do poder absolutista através de uma visão mítica da história como história natural, imutável, que dispensava a reflexão ética, na medida em que fazia com que o poder do soberano parecesse inquestionável. Mas, por outro lado, a alegoria barroca teria também um potencial crítico, desde que as imagens de destruição e ruína fossem interpretadas como descrições de um mundo ainda inacabado, em processo, e conseqüentemente mutável. Por trás do exagero e da pompa, o Barroco representava a decadência, o despedaçamento e a morte, como atestam as caveiras e outras imagens que faziam parte de um repertório rejeitado pelo Classicismo que, orientado pelos ideais de harmonia e totalidade, teria igual- 
mente rejeitado a alegoria devido a seu caráter fragmentário e polissêmico. $\mathrm{O}$ argumento já havia sido sugerido numa carta escrita por Benjamin a Scholem em 1917 num comentário a propósito de Picasso: a pintura não pode comunicar nenhuma essência, porque o lugar da essência não é a imagem, e sim o nome, que é desmascarado pela alegoria. Caso contrário, a pintura poderia se confundir com a filosofia.

O nome, em Origem do Drama Barroco Alemão, é o ser que determina o modo pelo qual as idéias são dadas, numa linguagem ou percepção primordial na qual as palavras têm, a despeito da sua função nomeadora, uma dimensão cognitiva. A idéia é representada como algo lingüístico, um elemento simbólico presente na essência da palavra. A tarefa do filósofo seria restaurar ou renovar este elemento, mediante uma reminiscência do ato nomeador no qual a palavra recebeu seu significado. "É por isso que a filosofia tem sido uma luta pela representação de algumas poucas palavras, sempre as mesmas - as idéias"(Benjamin 1, p. 59). Ao atribuir às idéias um surgimento, portanto uma origem, contrariando a posição romântica, Benjamin as insere na história. Idéias como "trágico" ou "cômico", por exemplo, não poderiam ser meros agregados de regras, mas idéias que não pretenderiam subsumir um certo número de obras com base em algum tipo de afinidade, que sobreviveriam mesmo se não existisse uma "tragédia pura" ou uma "comédia pura". Os gêneros artísticos seriam idéias, as obras de arte os fenômenos que permitiriam reconhecê-las.

O papel dos conceitos seria o de mediador, permitindo aos fenômenos participarem do ser das idéias, tornando-se aptos para uma tarefa filosófica: representar as idéias, que não podem se representar por si mesmas, mas unicamente por um ordenamento de configurações de elementos contidos nos conceitos. Elas representam os fenômenos na medida em que ordenam os conceitos que os circunscrevem. Mas não servem para conhecer os fenômenos, assim como estes não servem de critério para atribuir existência a elas. Para as idéias, a significação dos fenômenos se esgota nos elementos conceituais destes. Por sua existência, suas afinidades e diferenças, os fenômenos determinam o escopo e o conteúdo dos conceitos que os circunscrevem. As idéias determinam as relações de afinidade mútua entre estes conceitos.

A idéia seria uma palavra que um dia foi símbolo. Mas o momento histórico do ato de nomeação não pode ser repetido deliberadamente e a palavra passa para a esfera da mera comunicação. A alegoria seria importante por poder contar a história da palavra que já foi idéia, já que é uma imagem dessa linguagem, um reflexo do desejo de conhecer, sempre cerceado pela arbitrariedade 
dos sentidos. Sobre essa noção de alegoria, Benjamin ergueu sua crítica ao ideal artístico romântico de totalidade, de pureza e de unidade da significação. Da perspectiva da Origem do Drama Barroco Alemão, teria sido vedado ao Romantismo, assim como ao Classicismo, perceber na natureza aquilo que ela possui de heterônomo, incompleto e despedaçado, características exaltadas pelas formas extravagantes das alegorias.

As concepções de Walter Benjamin se contrapõem mais explicitamente às dos neokantianos, como Cassirer, Hermann Cohen e sobretudo Panofsky, que em Saturno e a Melancolia, publicado na mesma época em que Benjamin escrevia Origem do Drama Barroco Alemão, faz uma análise da forma alegórica a partir da gravura Melencolia I de Dürer, que interessou a Benjamin apenas como investigação iconográfica. Já Schopenhauer aparece em Origem do Drama Barroco Alemão como um classicista, um dentre os vários autores que teriam acreditado poder descartar a alegoria como expressão artística devido ao seu caráter arbitrário, inerente a todo sistema convencional de signos. Para ele, a verdadeira arte deveria exprimir uma Idéia concebida na sua mais completa pureza. Em outros termos, a arte deveria expressar uma Idéia, segundo a acepção platônica, intuída pelo gênio, homem de inteligência incomum, capaz de apreendê-la numa contemplação desinteressada. Não considerava a alegoria uma forma artística porque a compreendia como ilustração de um conceito e, portanto, como linguagem. Mas precisamente esta distinção entre "expressar uma idéia" e "expressar um conceito", que levou Benjamin a vê-lo como um classicista, corresponde a uma outra, fundamental no pensamento de Schopenhauer, entre conhecimento intuitivo e conhecimento abstrato.

O conhecimento intuitivo é, para Schopenhauer, uma função do entendimento que consiste unicamente em conhecer a relação entre cada efeito dado e sua causa, o que se dá de modo imediato. O entendimento, implicado em toda representação, é faculdade intelectual correspondente à matéria que, essencialmente, é causalidade, pois só pode ser percebida pelas modificações de seus estados na duração e na extensão. A partir deste argumento Schopenhauer pretende não apenas fundamentar, no quarto parágrafo de $O$ mundo como vontade e representação, a tese de que toda intuição é intelectual, como também apontar a inexatidão da expressão "sensibilidade pura", empregada por Kant para designar aquilo que entende como sendo o próprio entendimento. "Esta operação não é absolutamente uma conclusão tirada de dados abstratos, um produto da reflexão ou da vontade, ela é um conhecimento direto, necessário, absolutamente certo. Ela é o ato do entendimento puro, verdadeiro ato sem o 
qual jamais haveria uma intuição verdadeira do objeto, mas apenas uma consciência surda, vegetativa das modificações do objeto imediato; estas modificações se sucederiam sem apresentar qualquer sentido perceptível, exceto talvez para a vontade, a título de prazeres ou dores" (Schopenhauer 2, p. 19). À razão cabe apenas ampliar o conhecimento intuitivo, necessariamente particular e concreto, por meio de generalizações, que são os conceitos abstratos, os quais combina sob a forma de juízos e raciocínios, tornando possíveis a conservação e a transmissão do conhecimento, pré-requisitos para a constituição da ciência, das leis, do Estado e da linguagem.

As Idéias também estão vinculadas ao conhecimento intuitivo, mas essa relação é completamente diferente daquela que existe entre as intuições e os conceitos que, na sua generalidade, resultam da abstração dos dados particulares das representações, que são seu ponto de partida. $\mathrm{O}$ sujeito, em virtude das condições sensíveis e cerebrais da intuição, intui as Idéias fracionadas e disseminadas na pluralidade dos objetos individuais, mas essencial e originalmente cada Idéia é uma unidade que se transforma em pluralidade por meio do espaço e do tempo em formas que percebemos, podendo revelar o caráter próprio, a expressão completa de um ser percebido como objeto pela intuição. A Idéia de humanidade, por exemplo, é única, mas pode ser intuída tanto num quadro que retrate um importante acontecimento histórico como na pintura de uma cena do cotidiano.

A passagem do conhecimento comum das coisas particulares ao das Idéias se dá bruscamente, quando o sujeito deixa de ser simplesmente um indivíduo restrito a procurar relações conforme o princípio de razão para se absorver na contemplação profunda do objeto que se oferece a ele que, guiado pela força de sua inteligência, renuncia a considerar as coisas do modo habitual. Na contemplação estética a consciência deve ser inteiramente ocupada por uma visão intuitiva e única; o indivíduo precisa se libertar de toda relação com a vontade e, o objeto, de toda relação com aquilo que é estranho a ele. O que é conhecido é a Idéia, não mais o objeto particular, mas sua natureza objetiva, e quem conhece é o sujeito puro do conhecimento, não mais o indivíduo preso à dor, ao tempo. A vontade, que vincula o homem às coisas particulares, impedindo a contemplação das idéias, que estão fora de qualquer finalidade, é suprimida. Quando a serviço da vontade o homem é determinado pelas relações de seu corpo com outros corpos, sempre guiadas pelo princípio de razão e pelo interesse. Seu corpo é uma representação como as outras, um objeto entre outros. Suas ações seguem motivos que agem com a regularidade de leis físicas, assim 
como as modificações dos outros objetos se dão segundo causas e excitações.

A vontade que se manifesta no homem é a mesma vontade que se manifesta em tudo no mundo: nas forças naturais, no mundo inorgânico, nos vegetais e nos animais, o que não significa que cada ser tenha uma parte da vontade, pois esta não se submete à forma espacial que, assim como o tempo, é uma forma de conhecimento e, portanto, não apenas posterior à vontade, mas um produto desta, assim como os órgãos adequados ao conhecimento e mesmo a necessidade deste. Na contemplação estética o sujeito puro precisa suprimir sua vontade própria, que se refere à sua existência individual, para intuir esta vontade que se manifesta no mundo e que é a essência ou significado deste. A Idéia concebida na contemplação pura não é ainda a essência da coisa em si, mas aquilo que Schopenhauer chama de "objetidade imediata da vontade".

Se abstrairmos completamente o mundo considerado como representação não resta mais nada além do mundo considerado como vontade; a vontade constitui o "em si”" da idéia, que é a objetidade perfeita da vontade, assim como também constitui o "em si" da coisa particular e do indivíduo, que são objetidade imperfeita da vontade. Considerada independentemente da representação e de todas as suas formas, a vontade é una e idêntica no objeto contemplado e no indivíduo que, se elevando nesta contemplação, toma consciência dele mesmo como sujeito puro. Ambos se confundem porque são a vontade que conhece a si mesma. A pluralidade e a diferenciação, modalidades do conhecimento, existentes apenas no fenômeno e em virtude da sua forma, o princípio de razão, são eliminadas. Sem objeto ou representação, não sou sujeito do conhecimento mas simples vontade cega. Do mesmo modo, sem o eu, sem sujeito do conhecimento, a coisa conhecida não pode ser objeto, e permanece simples vontade, impulso cego. Esta vontade é em si, ou seja, fora da representação, una e idêntica à minha. Apenas no mundo considerado como representação, submetido à sua forma mais geral, que é a distinção entre sujeito e objeto, ocorre a distinção entre indivíduo que conhece e objeto que é conhecido. Basta suprimir o conhecimento para que o mundo considerado como representação seja definitivamente simples vontade.

A apreensão da Idéia necessária para a verdadeira arte exige uma modificação no sujeito, que precisa abandonar seu modo habitual de conhecer para ser absorvido pelo objeto que a ele se oferece, seja ele artístico ou natural. Tal contemplação deve também ser desinteressada porque, se no mundo dos fenômenos o homem está sempre a procurar relações que por fim se reduzem à relação que estes mantêm com a sua vontade, a contemplação da Idéia não 
procura qualquer relação temporal, espacial, ou de finalidade. O princípio de razão é inteiramente excluído desta esfera, já que pertence ao domínio do conhecimento racional, que se dá por conceitos, generalizações úteis na vida prática e nas ciências.

O conceito seria como um recipiente inanimado, do qual é impossível retirarmos qualquer coisa além daquilo que nele colocamos, e a idéia como um organismo vivo. Por isso Schopenhauer considera o conceito, a despeito de sua utilidade na vida prática e nas ciências, completamente estéril para a arte. Conceitos seriam representações que concentrassem aquilo que há de geral nas intuições, palavras seriam os signos sensíveis dos conceitos, meios necessários para fixá-los e torná-los presentes para a consciência. A linguagem, por sua vez, é entendida meramente como um sistema de signos que representam esses conceitos (Schopenhauer 3, p. 738). Por serem representações gerais obtidas pela abstração e diferentes dos objetos particulares, os conceitos teriam uma existência objetiva, alheia a qualquer série temporal. Para que se apresentem prontamente para uma consciência individual, podendo ser intercalados numa série temporal e de algum modo chegar ao estado de objetos particulares, devem ser individualizados e ligados a uma representação sensível, que seria a palavra. Assim se estabelece uma ligação entre a razão, cujos objetos puramente gerais são universais que não conhecem nem o tempo nem o espaço, e a consciência sensível, ligada ao tempo. Graças às palavras podemos reproduzir, evocar e conservar os conceitos e efetuar operações como julgar, concluir, ou comparar. Embora a linguagem seja um instrumento indispensável para um pensamento claro, por limitar os significados, ela restringe a liberdade de pensamento ${ }^{2}$.

As alegorias estão sujeitas às mesmas condições que o conceito, já que Schopenhauer as compreende como imagens escolhidas deliberadamente para ilustrá-los, para expressar algo que é abstrato, estranho à esfera da arte. No cumprimento deste papel a perfeição artística não é obrigatória: basta tornar o objeto reconhecível. É por isso que nas artes plásticas as alegorias "não passam de hieróglifos", pois o valor artístico que possam ter como representações intuitivas não lhes pertence enquanto alegorias, mas por outros motivos. Para poder admitir que uma obra alegórica pudesse ter valor artístico, Schopenhauer estabeleceu uma distinção entre significação nominal e significação real (cf. Schopenhauer 2, p. 305). A significação nominal seria a da alegoria considerada como tal, e a significação real aquela que é efetivamente representada e que exprime uma Idéia. A significação real só tem efeito se abstrairmos esta significação nominal e alegórica. Freqüentemente esta significação nominal, 
esta intenção alegórica, prejudica a significação real, a verdade concreta, pois quando nos lembramos dela abandonamos a contemplação e nosso espírito passa a ser ocupado por um conceito abstrato. As piores alegorias seriam aquelas nas quais não se apresentasse sequer alguma associação de idéias que relacionasse a imagem e o conceito, sendo o vínculo entre eles apenas convencional, chamadas por Schopenhauer de "alegorias simbólicas".

"É assim que a rosa é o símbolo da discrição; o louro é o símbolo da glória; a palma é o da vitória; a concha o da peregrinação; a cruz o da religião cristã. Nesta mesma categoria estão as significações que damos às cores: o amarelo representa a falsidade, o azul, a fidelidade etc. Tais símbolos podem ter um uso muito freqüente na vida, mas eles nada significam do ponto de vista da arte. Devemos ver neles algo como a caligrafia chinesa, ou os hieróglifos. São como os escudos que servem de insígnias aos albergues, ou a chave que distingue o maçom. Chamo de emblemas aqueles símbolos que são admitidos definitivamente como atributos de um personagem histórico ou mítico, como característica de uma noção personificada; tais são os animais dos evangelistas, a coruja de Minerva, a maçã de Paris, a âncora da esperança." (Schopenhauer 2, p. 307).

Mas se para Schopenhauer a alegoria nas artes plásticas é entendida como uma frivolidade, algo corrompido e incorreto, que corre o risco de se tornar insuportável a partir do momento em que passa a representar interpretações forçadas e bizarras, na poesia ela é, ao contrário, bem-vinda, pois confere a possibilidade da intuição. Nas artes plásticas ela conduz do dado intuitivo, objeto próprio de toda arte, ao pensamento abstrato. Já na poesia, a relação é inversa. Aqui, o que é diretamente oferecido pelas palavras é o conceito. O fim do artista é sempre o de conduzir do conceito à intuição, que a imaginação do auditor/leitor deve se encarregar de representar. Nas artes plásticas o dado direto conduz a uma outra percepção, que só pode ser uma abstração, pois o que é apenas abstrato não pode ser representado imediatamente. Já um conceito não poderia jamais ser o ponto de partida, e nem sua comunicação poderia ser o fim de uma obra de arte. Mas a matéria da poesia é o conceito, ele é o dado imediato. E podemos perfeitamente partir dele para evocar uma representação intuitiva. Em um poema é indispensável recorrer a muitos conceitos ou pensamentos abstratos que não são suscetíveis de qualquer representação intuitiva. Assim, os representamos freqüentemente para a intuição nos valendo de exemplos 
intermediários, que possam ser subsumidos sob o pensamento abstrato. Este fenômeno se produz em todas as expressões figuradas, metáforas, comparações, parábolas e alegorias, que nelas mesmas não são verdadeiramente arte.

A presença de Schopenhauer em Origem do Drama Barroco Alemão, para mostrar a exclusão da linguagem do campo das artes visuais, ainda que sob a forma de símbolo ou alegoria, nos interessa não para refletir sobre a gênese da linguagem em Schopenhauer, mas por evidenciar que ao discurso é negado um papel na estética (mesmo na poesia a palavra precisa ser convertida em imagem para que se preste à contemplação), por exigir esforço para ser compreendido, direcionando o intelecto conforme fins, o que implica interesse e atividade da vontade, o que não pode ser admitido na arte, que n' $O$ mundo como vontade e representação, além de ser uma consolação para o sofrimento, representa uma etapa que antecede a verdadeira filosofia na renúncia ao querer viver e no conhecimento puro da verdadeira natureza do mundo.

\footnotetext{
Abstract: The aim of the text is to investigate Benjamin's critique to the romantic notion of allegory and its relationship with the role of language in Schopenhauer's philosophy, mainly concerning about the exclusion of language from aesthetics.
}

Key-words: symbol -allegory - Idea - concept 


\section{Notas}

1. Reproduzimos a passagem do $\S 50$ do Mundo como vontade e representação tal como esta é citada por Walter Benjamin (Benjamin 1, p. 183-4).

2. Este inconveniente pode em parte ser contornado quando se aprende várias línguas, pois passando de uma à outra o pensamento se modifica, se desembaraça, e sua essência íntima se manifesta mais claramente (Schopenhauer 2, p. 742).

\section{Referências Bibliográficas}

1. BENJAMIN, W. Origem do drama barroco alemão. Trad. S.P. Rouanet. São Paulo, Brasiliense, 1984.

2. SCHOPENHAUER, A. O mundo como vontade e representação. Trad. M.F. Sá Correia. Porto, Rés, s/d.

3. " "Suplementos ao mundo como vontade e representação". In: Le monde comme volonté et représentation. Trad. A. Burdeau, Paris, P.U.F., 1992. 